\title{
Epidemia de tifus exantemático en Chile (1932-1939)
}

\author{
Enrique Laval
}

\section{Exanthematic typhus epidemic in Chile}

(1932-1939)
Pontificia Universidad Católica de Chile Facultad de Medicina Programa de Estudios Médicos Humanísticos

Recibido: 23 de septiembre de 2012

Correspondencia a:

Enrique Laval

revinf@sochinf.cl effective insecticides and the discovery of an effective antibiotic treatment (chloramphenicol).

Key words: Exanthematic typhus, history, outbreak, treatment.

Palabras clave: Tifus exantemático, historia, epidemia, tratamiento.

\section{Introducción y antecedentes históricos}

A 1 redescubrir la existencia del tifus exantemático en Chile, a mediados del siglo XIX, el estudiante de $6^{\circ}$ año de Medicina, don Florencio Middleton, empleó para describirlo el nombre de "typhusfever", separándolo netamente de la fiebre tifoidea. Esta memoria la presentó a la Facultad de Medicina y fue premiada en el certamen de 1867, curiosamente "como el mejor trabajo sobre fiebre tifoidea", lo que indiscutiblemente indicaba la confusión entre ambas enfermedades desde los albores de la Colonia y por supuesto mereció ser publicada en los Anales de la Universidad de Chile de $1871^{1}$.

En 1906, después de unos diez años silenciosos, reaparece en Valparaíso, produciéndose 30 casos, para luego desaparecer hasta 1918, reemergiendo y coincidiendo con la epidemia de influenza, parte de la pandemia de dicha enfermedad en aquel año $0^{2-4}$.

Como lo recuerdan Atilio Machiavello y Osvaldo Cifuentes, en esta época se introducen los métodos diagnósticos de laboratorio para el estudio del tifus exantemático en Chile. Vega Montalba es el primero en transmitir experimentalmente la enfermedad al cobayo y Laval Manrique, en practicar la reacción de Weil-Félix, en 1919, como método de rutina. El doctor Arturo Atria Osorio, realiza importantes investigaciones históricas, demostrando que el tifus exantemático "había existido siempre en Chile, como una enfermedad endémica con recrudescencias epidémicas periódicas". Al convertirse la gran epidemia de 1918 en endemia, en 1926, nuevamente la enfermedad deja de preocupar la atención médica, hasta que en 1932, con la iniciación de un nuevo ciclo epidémico, vuelve a despertar entre los investigadores el afán de estudiar

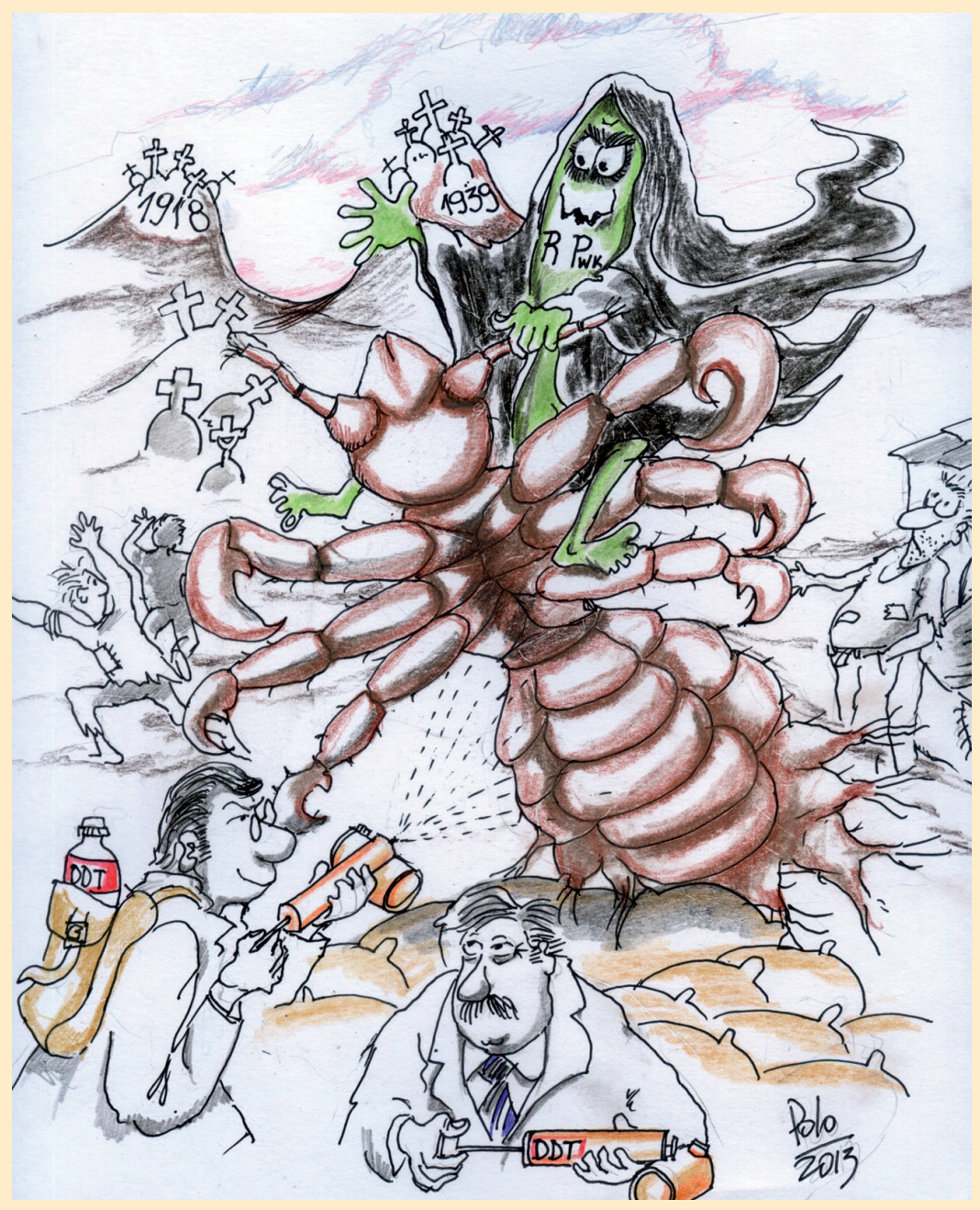

www.sochinf.cl 
la enfermedad, esta vez, en forma científica, de acuerdo con las facilidades médicas del país ${ }^{4-8}$.

Hasta 1918, el tifus exantemático no aparece entre las causas de muerte, aunque ya en 1915-16 se había comenzado a presentar en las cárceles de Santiago.

Entre 1918 y 1939, se registraron en Chile 87.400 casos y 18.484 defunciones, pero se presume que ascendió a más de 100.000 .

\section{La epidemia de 1932 a 1939. Compromiso cardíaco, nervioso y ocular}

Sólo a fines del invierno de 1932 adquiere la enfermedad nuevamente carácter epidémico, primero en la provincia de Concepción y después en las de Cautín y Ñuble. En el año 1933, la mayoría de las provincias fueron invadidas, con especial gravedad en Santiago, Concepción, Ñuble, Biobío y Cautín?.

El número de enfermos consignados por la Dirección General de Sanidad, desde 1932 a 1939, fue de 45.891 y la suma de los años 1933-1934, $30.070(66 \%)^{7}$.

Rosa Urrutia y Carlos Lazcano relatan lo siguiente: “en 1932 el país sufrió una fuerte crisis económica, paralizando las salitreras. Los obreros cesantes llegaron a Santiago y a otros lugares en gran número, ubicándose en albergues, lo que favoreció la aparición del tifus exantemático, extendiéndose la epidemia rápidamente, favorecida por las malas condiciones higiénicas de la época. A partir de 1933, se tomaron diversas medidas de emergencia para evitar su propagación: suspensión de las clases en los colegios durante 10 días para desinfectar las aulas; a los empleados públicos se les fijo una jornada única por 18 días, para descongestionar los autobuses y tranvías. El Presidente de la República y los ministros suspendieron las audiencias por 10 días; los teatros cerraron por cinco días y luego abrieron sin ocupar los anfiteatros y las galerías. Fueron suspendidas las carreras en el hipódromo y los espectáculos deportivos, para salvaguardar la higiene pública. Se impidió, incluso con fuerza pública toda fiesta o reunión que se realizara al margen de las disposiciones oficiales.

El arzobispado de Santiago cedió un lugar para los servicios de desinfección, disponiéndose que las celebraciones religiosas se suspendieran por 8 días, entre Santiago y Chiloé, para proceder a la desinfección de los templos. Se empadronaron todos los suplementeros y se les efectuó una desinfección, suspendiéndose por algunos días, la venta de periódicos en el centro de la ciudad. Finalmente se tendió un cordón sanitario en Santiago, con brigadas en los caminos de acceso al puente Maipo y en otros puntos. La Cruz Roja hizo una colecta para juntar fondos destinados para confeccionar ropa para los cesantes y tifosos de los hospitales, la mayoría de los cuales quedaban sin nada para ponerse, cuando su vestuario era llevado a los desinfectorios"10.
En 1933 comenzaron a aislarse los enfermos de Santiago en el Regimiento Cazadores ("Hospital Cazadores"), habilitándose en 1934 el Hospital Ramón Barros Luco, que hasta ese momento se encontraba desocupado.

La Beneficencia había dispuesto 542 camas para el aislamiento de estos enfermos y a fines de 1934, en el hospital ya señalado, se encontraban en funciones 150 , aumentando a 270 posteriormente. Por lo tanto, el Hospital Ramón Barros Luco proporcionó la mitad de las camas para la atención de los enfermos con tifus exantemático de la provincia de Santiago.

Como la epidemia aumentaba en forma vertiginosa, fue necesario clausurar el policlínico del hospital, para internar más enfermos, contratándose personal para la emergencia.

Cuenta el doctor Kraus que "desde la aparición del primer caso de tifus exantemático, al iniciarse la década de 1930, se llevó a la práctica todas las medidas de profilaxis necesarias, comenzándose de inmediato la campaña de desinsectización, con una gran propaganda por medio de la prensa, carteles y volantes a favor de la conveniencia de exterminar los parásitos y recomendando a la población bañarse con frecuencia"11-13.

Abraham Horwitz y Conrado Ristori señalaron el aspecto clínico del tifus exantemático en esta última epidemia, de acuerdo a lo observado en 627 enfermos internados en el Hospital Ramón Barros Luco, entre junio y octubre de 1939, de acuerdo a un esquema preestablecido por la Dirección General de Sanidad, lo que permitió conocer en líneas generales, las características clínicas de la epidemia. El porcentaje global de letalidad fue de $20,5 \%$ y el mayor número de casos se produjo en los meses de invierno, a diferencia del año 1938, que alcanzó su acmé en primavera, adelantándose con respecto a las anteriores, recordando el ritmo epidemiológico del tifus exantemático en Europa.

No hicieron mayores comentarios sobre la influencia del factor "categoría social" de los enfermos, ya que es un hecho bien establecido que el "tifus exantemático es parte de la miseria". El sexo y la edad los consideraron conjuntamente con los caracteres clínicos más importantes, estudiando sucesivamente esta epidemia en el niño y en el adulto.

Esta epidemia se caracterizó por ser más frecuente y de mayor gravedad en el hombre, así como también la presencia de alteraciones del sistema nervioso, dominando las complicaciones del aparato respiratorio y la presencia de escaras ${ }^{14}$.

Alejandro Garretón, Luis Hervé y Antonio del Solar, expusieron las alteraciones en las curvas electrocardiográficas de 85 enfermos de tifus exantemático, atendidos en el Hospital San Francisco de Borja de Santiago. El análisis de 260 trazados mostró, que en 80 de los enfermos (94\%), existió compromiso cardíaco, comprobando que 
las alteraciones electrocardiográficas eran más acentuadas, cuando más grave era la infección. La letalidad de los enfermos estuvo estrechamente ligada a las alteraciones del complejo ventricular, lo cual sucedió en $85 \%$ de los casos.

Los autores, junto con el patólogo doctor Héctor Rodriguez, completaron su trabajo con un estudio histopatológico del miocardio en 32 fallecidos a consecuencia del tifus exantemático, siendo la lesión característica la miocarditis aguda, que representa una localización de la endocapilaritis, lesión circulatoria fundamental de dicha enfermedad infecciosa.

Sin embargo, la miocarditis del tifus exantemático, puede curar completamente, como lo demostraron en el estudio histopatológico del miocardio de tres enfermos que fallecieron por otras causas, después de finalizada la evolución del tifus. Todas las lesiones habían desaparecido, quedando como secuelas reacciones conjuntivales fibroblásticas ${ }^{15}$.

Según Rodolfo Núñez, el tifus exantemático compromete siempre el sistema nervioso, produciendo una encefalomielitis aguda y la mayoría de los autores acepta que las lesiones microscópicas predominan en la región bulbo-protuberancial. Las verdaderas complicaciones son las que persisten o se presentan después de la defervescencia, como los temblores y las neuritis.

Durante el período febril hubo casi siempre delirio psicomotor, más tarde estupor confusional y a veces estado comatoso. Más raras fueron las hemorragias meníngeas con convulsiones.

En las complicaciones neurológicas con hipertensión endocraneana, el líquido cefalorraquídeo, reveló linfocitosis con o sin hiperalbuminosis.

En general, las complicaciones neurológicas tuvieron carácter francamente regresivo; con más probabilidades de mejoría, que en los síndromes semejantes de etiología diferente ${ }^{16}$.

El doctor Raúl Costa Lennon, de la Clínica Universitaria Oftalmológica del Hospital del Salvador de Santiago, respecto a las lesiones oculares del tifus exantemático, concluye de todo lo observado durante la epidemia, que "las alteraciones de la visión son relativamente frecuentes, ya sea por "toxicosis" o bien "por disminución de las resistencias que lleva consigo". Como enfermedad infecciosa puede ocasionarlas en todos sus períodos de evolución. Estas manifestaciones, sobre todo las producidas por la "toxina microbiana" en el fondo del ojo, son de orden vascular, con frecuencia graves y pueden conducir a la ceguera parcial o total ${ }^{17}$.

\section{Disminución de la epidemia. Tratamiento de la enfermedad y erradicación del transmisor}

Desde 1935 se observó una franca disminución de la epidemia, con reducción importante de los casos, notifi- cándose en el año 1938, solo 829. Sin embargo, hubo un repunte moderado del brote durante 1939 , alcanzando a 1.439 casos.

Conviene recordar que el 24 de enero de ese último año, se produjo el llamado "terremoto de Chillán", que asoló la zona centro sur del país, pudiendo haber influido en empeorar el estado sanitario de Chile, quizás con un nuevo y mayor brote de tifus exantemático. Pero afortunadamente, el Presidente de la República don Pedro Aguirre Cerda, nombró al doctor Víctor Grossi de la Cuadra, como jefe de todos los servicios sanitarios y médicos de las regiones dañadas por el sismo. Gracias a su inteligente y abnegada labor se pudo evitar epidemias, realizándose una atención médica de urgencia de gran calidad ${ }^{18}$.

En aquel tiempo todavía no se contaba con un tratamiento eficaz para destruir la Rickettsia prowazeckii, causante del tifus exantemático epidémico, ni tampoco existía un producto efectivo para aniquilar el trasmisor, el Pediculus humanus corporis. Faltarían nueve años para que se descubriera el antibacteriano que cumpliera con la primera misión señalada: el cloranfenicol. Menos tiempo se necesitó para obtener un insecticida que destruyera al Pediculus ("piojo del hombre"), ya que en 1943 comenzó a utilizarse el DDT (dicloro-difenil-tricloroetano), el que fue prohibido en el país a contar de 1985, debido a su alta toxicidad, existiendo ya pesticidas menos dañinos para la salud.

Las provincias de Malleco, Cautín, Llanquihue y Chiloé (regiones IX, X y XI), constituyeron las zonas de máximo peligro epidemiológico, siendo casi siempre el punto de origen de los brotes, el departamento de Imperial.

En 1948 se produjo el último brote de importancia en las provincias del sur, con 1.235 enfermos y 59 fallecidos ${ }^{19}$.

\section{Resumen}

Después de la gran epidemia de tifus exantemático de 1918-1919 en Chile, hubo una disminución paulatina del número de casos, hasta transformarse en endemia, alrededor de 1926. A partir de 1932 y hasta 1939, se produjo un nuevo brote epidémico, que instó a los investigadores a su estudio a través de los nuevos avances de la clínica y tecnología de la época. Posteriormente se originaron dos sucesos importantes: la erradicación del vector ("piojo del hombre") por medio de insecticidas eficaces y la aparición de un tratamiento antibacteriano (cloranfenicol) efectivo.

\section{Referencias bibliográficas}

1. Middleton F. Memoria sobre la epidemia de "typhusfever". AUCH 1871; 38: 229-402. 
2. Vial H M. Tifus exantemático en Valparaíso. Rev Chil Hig 1907; 16: 273.

3. Laval R E. Chile 1918: las dos epidemias. Rev Chilena Infectol 1999; 16: 273.

4. Vega M E. Trasmisión experimental del tifus exantemático al cobayo. Rev Chil Hig 1919; 25: 168.

5. Laval M E. Epidemia de tifus exantemático en Chile. 1918 An Chil Hist Med. 1964; 6: 335-47.

6. Laval M E. La reacción del Weil-Félix en el tifus exantemático. Rev Chil Hig 1919; 25:190.

7. Machiavello A, Cifuentes O. El tifo exantemático en Chile Rev Chil Hig y Med Prev 1942; 5: 109-29.

8. Atria O A. Sobre tifus exantemático. Impta. Franco chilena 1919.

9. Tifus exantemático. 1931-1937. Rev Med e Hig Prev 1937; $1: 35-8$.

10. Urrutia R, Lanza L C. Catástrofes en Chile. 1541-1992. Ed. La Noria. Santiago de Chile. 1993.

11. Laval M E. Cronología de los principales antecedentes y sucesos que llevaron a la construcción del Hospital Ramón Barros Luco. (1888-1935). An Chil Hist Med 2007; 17: 221-6.

12. Kraus R. La Sanidad en Chile. Labor desarrollada por los servicios sanitarios de Chile. Junio 1930 a junio 1931 Maffet, H.A. El cuerpo médico y la medicina chilena. Santiago de Chile. 1939.

13. Guzmán L. Disertación sobre tifus exantemático. Aislamiento de los enfermos en el Regimiento Cazadores. ("Hospital Cazadores"). Rev Med Chile 1934; 62: 124-5.

14. Horwitz B A, Ristori C C. Aspecto clínico del tifus exantemático en la última epidemia (junio a octubre de 1939). Rev Med Chile 1940; 68: 1016-25

15. Garretón S A, Hervé L L, Del Solar A. Las alteraciones electrocardiográficas en el curso del tifus exantemático. Rev Med Chile 1935; 63: 652-3.

16. Núñez R. Síndromes neurológicos tíficos y post-tíficos. Rev Med Chile 1936; 64: 586-95.

17. Costa L R. Lesiones oculares del tifus exantemático. Rev Med Chile 1934; 62: 552-70.

18. Laval R E. El terremoto del 24 de enero de 1939 y el doctor don Víctor Grossi de la Cuadra. An Chil Hist Med 2007; 17 : 53-9.

19. Pino C F. El tifo exantemático en Chile. (apuntes). Cátedra de Epidemiologia. Escuela de Salubridad. Universidad de Chile. 1956. 